\title{
Bradykinin enhances membrane electrical activity of pancreatic beta cells in the presence of low glucose concentrations
}

\section{A.S. Moura}

\section{Correspondence}

A.S. Moura

Beth Israel Deaconess Medical Center

Department of Medicine

Division of Endocrinology

Harvard Medical School

330 Brookline Ave.

Research North

Boston, MA 02215

USA

Fax: + 1-617-667-3249

E-mail: asmoura@uerj.br

Research supported by CNPq (No. 520106/96) and

FAPERJ (No. E-26/171300/95).

Received July 16, 1999

Accepted June 9, 2000
Laboratório de Fisiologia Celular, D epartamento de Fisiologia,

Universidade do Estado do Rio de Janeiro, Rio de Janeiro, RJ, Brasil

\section{Abstract}

In most of cells bradykinin (BK) induces intracellular calcium mobilization. In pancreatic beta cells intracellular calcium is a major signal for insulin secretion. In these cells, glucose metabolism yields intracellular ATP which blocks membrane potassium channels. The membrane depolarizes, voltage-dependent $\mathrm{Ca}^{2+}$ channels are activated and the intracellular calcium load allows insulin secretion. Repolarization occurs due to activation of the $\mathrm{Ca}^{2+}$-dependent $\mathrm{K}^{+}$channel. The insulin secretion depends on the integrity of this oscillatory process (bursts). Therefore, we decided to determine whether BK (100 nM) induces bursts in the presence of a non-stimulatory glucose concentration (5.6 $\mathrm{mM}$ ). During continuous membrane voltage recording, our results showed that bursts were obtained with $11 \mathrm{mM}$ glucose, blocked with $5.6 \mathrm{mM}$ glucose and recovered with $5.6 \mathrm{mM}$ glucose plus $100 \mathrm{nM}$ BK. Thus, the stimulatory process obtained in the presence of BK and of a non-stimulatory concentration of glucose in the present study suggests that BK may facilitate the action of glucose on beta cell secretion.

\section{Key words}

- Membrane potential

- Pancreatic beta cell

- Bradykinin

- Calcium
Bradykinin (BK) is a nonapeptide formed by the action of a serine protease called kallikrein $(1,2)$. The kinins produced by this protease are largely released into blood, interstitial fluid and glandular tissue, in particular by the pancreas (3). Recently, the involvement of BK has been shown in the secretion of insulin. For instance, the presence of BK receptors was found in rat pancreas (4). The binding between the nonapeptide and its receptor has been suggested as being responsible for an increase in insulin release (5). Our laboratory, studying the role of calcium in this process, has shown an association between the beta cell ${ }^{45} \mathrm{Ca}$ efflux and insulin secretion during BK action (6).

In pancreatic beta cells glucose is the main promoter of the insulin stimulus-secretion process. Soon after intracellular glucose metabolism, the membrane displays voltage oscillations with depolarizations sustained for a brief period of time (about $15 \mathrm{~s}$ ), followed by repolarization (bursts). Today it is well known that glucose-induced depolarization is caused by the increase in cytosolic ATP or the ATP/ADP ratio, which acts by closing $\mathrm{K}^{+}$channels. The increased cytosolic $\mathrm{Ca}^{2+}$ opens the $\mathrm{Ca}^{2+}$-sensitive $\mathrm{K}^{+}$channels 
and contributes to membrane repolarization (7). It has been suggested that the islet intercellular spaces provide most of the calcium responsible for the cytosolic concentration of this ion (8). The process of insulin-stimulated secretion is the result of coupling between its action on the membrane and glucose metabolism on cytosolic environment. However, this process has not been observed in beta cells in media when glucose concentration is less than $11 \mathrm{mM}$.

The present study was designed to test the hypothesis that BK is able to facilitate bursts in the presence of low glucose concentrations. Therefore, the main rationale is based on the fact that the observed physiological increase in BK, in specific physiological situations, for instance during cardiovascular dynamic modulation (9), may provide an alternative route for the modulation of insulin secretion.

The experiments were performed in Langerhans islets microdissected from mouse pancreas. An isolated islet was placed in a $40-\mu \mathrm{l}$ chamber and perfused at a rate of $1 \mathrm{ml} /$ min with a solution of the following composition: $120 \mathrm{mM} \mathrm{NaCl}, 25 \mathrm{mM} \mathrm{NaHCO} 3,5$ $\mathrm{mM} \mathrm{KCl}, 2.5 \mathrm{mM} \mathrm{CaCl}_{2}$ and $1.1 \mathrm{mM} \mathrm{MgCl}_{2}$. Eleven or $5.6 \mathrm{mM}$ glucose and $100 \mathrm{nM}$ bradykinin were added as required. The solution was continuously equilibrated with $95 \% \mathrm{O}_{2} / 5 \% \mathrm{CO}_{2}, \mathrm{pH} 7.4$, at $37^{\circ} \mathrm{C}$. Bradykinin and all other reagents were obtained from Sigma Chemical Co. (St. Louis, MO, USA).

The electrophysiological method used to measure the membrane potential has been described elsewhere (10). Briefly, a single islet (200 to $500 \mu \mathrm{m}$ in diameter) was placed in a perfusion chamber and impaled with thick-walled microelectrodes of high resistance (150 to $250 \mathrm{M} \Omega$ ) filled with $2 \mathrm{M} \mathrm{KCl}$. The intracellular microelectrode and extracellular electrode (reference) were electrically connected to a differential voltage electrode through an $\mathrm{Ag} / \mathrm{AgCl}$ wire. The membrane potential signal was displayed on an oscilloscope (Tektronix R516B) and on a potentiometer recorder (Gould Brush 260). The data were also stored on a record tape recorder (Hewlett Packard 3690 Instrumentation Recorder).

Figure 1 shows the action of BK on the beta cell membrane potential in the presence of a stimulatory (11 $\mathrm{mM})$ and a non-stimulatory glucose concentration $(5.6 \mathrm{mM})$. We first showed that in the absence of any stimulus the membrane was negative (around -60 to $-70 \mathrm{mV}$ ) and with glucose stimulation it oscillated between a depolarized plateau potential (around -40 to $-30 \mathrm{mV}$ ). Superimposed on the plateau are action potentials triggered by the activation of voltage-dependent $\mathrm{Ca}^{2+}$ channels (11). Figure 1 shows the characteristic electrical activity of the beta cell membrane (bursts) induced by 11 $\mathrm{mM}$ glucose (panel A). The membrane did not depolarize electrically when glucose concentration was decreased from $11 \mathrm{mM}$ to 5.6 $\mathrm{mM}$ (panels A and B). The addition of 100 $\mathrm{nM} \mathrm{BK}$ to the perfusion solution containing $5.6 \mathrm{mM}$ glucose induced a membrane depolarization and a sustained train of spikes (Figure 1, panels C and D), whereas the bursts were not sustained when BK was not added to this solution (Figure 1, panels E and F). The electrical activity was recovered with $11 \mathrm{mM}$ glucose (Figure 1, panels $\mathrm{F}$ and $\mathrm{G}$ ). These data agree with our previous experiment, which showed that BK has a stimulatory effect on the beta cell membrane electrical activity (6), and the appearance of bursts in the presence of $5.6 \mathrm{mM}$ glucose clearly demonstrated the effect of BK in the presence of a non-stimulatory glucose concentration.

One hypothesis to explain the bursts in the presence of $5.6 \mathrm{mM}$ glucose, observed here for the first time at this glucose concentration, may be the effect of BK on membrane permeability. For instance, a shifting of the membrane potential equilibrium has been shown in other cells, such as those of the neuroblastoma x glioma hybrid NG108- 
15. In these cells the changes of membrane potential equilibrium obtained by the presence of different $\mathrm{K}^{+}$concentrations were synergistically enhanced by the presence of BK. Also, BK-induced inositol 1,4,5-triphosphate $\left(\mathrm{IP}_{3}\right)$ generation was enhanced in these cells, allowing a strong metabolic pathway to trigger $\mathrm{Ca}^{2+}$ release from internal $\mathrm{Ca}^{2+}$ pools $(12,13)$. These observations suggest that BK may also reduce the threshold to glucose stimulation on beta cell membranes due to changes in the electrochemical driving force.

Our observations, taken together with recent evidence that the intracellular $\mathrm{Ca}^{2+}$ in the submembrane space, rather than the average cytoplasmatic concentration of this ion, plays a major role in the electrical beta cell setting activity $(14,15)$, indicate that this is a system of high sensitivity. In other words, it may be hypothesized that the action of BK increasing the spike frequency due to the intracellular $\mathrm{Ca}^{2+}$ release (6) and movement towards a cytosolic environment closer to the membrane may explain why BK may facilitate the action of glucose on beta cell secretion.

Our data, considered as a whole, suggest that BK may have a permissive action on pancreatic beta cell electrical activity. This activity, which is strongly associated with insulin secretion $(4,5,16,17)$, and the described improvement in muscle insulin sensitivity induced by BK (18) may be related to

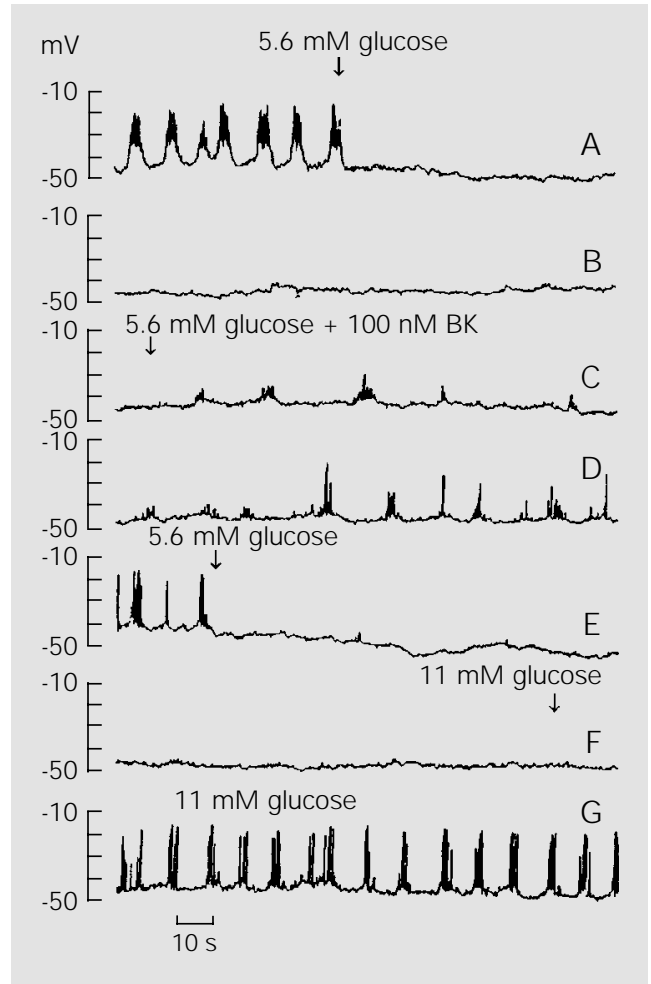

certain physiological conditions in which the demand for insulin is higher than in a normal glycemic situation.

The mechanisms underlying the action of $\mathrm{BK}$ are beyond the objective of the present study. However, the data, taken together, support the possibility that BK may be produced at different concentrations in blood or locally and may at least participate in the modulation of insulin secretion.
Figure 1 - Effect of bradykinin (BK) plus a non-stimulatory glucose concentration on beta cell electrical activity (bursts). Panels $A$ and $B$, Characteristic pattern of membrane electrical activity obtained with a stimulatory glucose concentration (11 mM) replaced with a non-stimulatory glucose concentration $(5.6 \mathrm{mM})$ and the depolarizations were blocked. Panels C, D and E, One hundred $\mathrm{nM}$ BK was added to the previous solution $(5.6 \mathrm{mM}$ glucose) and the membrane recovered electrical activity. The absence of $100 \mathrm{nM}$ BK in E abolished the occurrence of bursts and the addition of $11 \mathrm{mM}$ glucose in $\mathrm{F}$ restored the membrane electrical activity (panel G). The membrane potential $(\mathrm{mV})$ was recorded from an impaled cell of a microdissected pancreatic islet using a glass microelectrode as previously described. Representative traces from at least eight experiments are shown in each panel. The arrows refer to the time of addition or removal of the experimental solution. The records were obtained from the same continuously perfused cell.

\section{References}

1. Rocha e Silva M, Beraldo WT \& Rosenfeld G (1949). Bradykinin, a hypotensive and smooth muscle stimulating factor released from plasma globulin by snake venom. American J ournal of Physiology, 156: 261-273.

2. Regoli D \& Barabe J (1980). Pharmacology of bradykinin and related kinins. Pharmacological Reviews, 32: 1-46.

3. Amouric M \& Figarella C (1979). Characterization and purification of kallikrein from human pancreatic juice and immunologi- cal comparison with other kallikreins. Hoppe-Seyler's Zeitschrift für Physiologische Chemie, 360: 457-465.

4. Gerald WL \& Chao L (1986). Immunological identification of rat tissue kallikrein cDNA and characterization of the kallikrein gene family. Biochimica et Biophysica Acta, 866: 1-4.

5. Yang C \& Hsu W (1995). Stimulatory effect of bradykinin on insulin release from the perfused rat pancreas. American J ournal of Physiology, 268: E1027-E1030.
6. Moura AS, Filho J SC \& Franco de Sá CCN (1998). Bradykinin action on the membrane potential, ${ }^{45} \mathrm{Ca}$ efflux and insulin secretion of pancreatic beta cells. Medical Science Research, 26: 825-827.

7. Ashcroft FM, Harrison DE \& Ashcroft SJ (1984). Glucose induces closure of single potassium channels in isolated rat pancreatic ß-cells. Nature, 312: 446-448.

8. Moura AS (1995). Membrane potential and intercellular calcium during glucose challenge in mouse islet of Langerhans. 
Biochemical and Biophysical Research Communications, 214: 798-802.

9. Miantello RM, Damiani MT \& Wolly HL (1998). Cardiovascular kinin-generating capability in hypertensive fructose-fed rats. J ournal of Hypertension, 16: 12731277.

10. Atwater I, Ribalet B \& Rojas E (1979). Mouse pancreatic ß-cells: tetraethylammonium blockage of the potassium permeability increase induced by depolarization. J ournal of Physiology, 288: 561-574.

11. Ashcroft FM \& Rorsman P (1990). ATPsensitive $\mathrm{K}^{+}$channels: link between ß-cell metabolism and insulin sensitivity. Biochemical Society Transactions, 18: 109111.

12. Berridge MJ (1993). Inositol triphosphate and calcium signaling. Nature, 361: 315325.

13. Chuem S-H \& Kao L-S (1994). Calcium signaling induced by bradykinin is synergistically enhanced by high $\mathrm{K}^{+}$in NG-10815 cells. American J ournal of Physiology, 35: C10006-C10012.

14. Rojas E, Carroll PB, Ricordi C, Boschero AC, Stojilkovic SS \& Atwater I (1994). Control of cytosolic free calcium in cultured human pancreatic ß-cells occurs by external calcium-dependent and independent mechanisms. Endocrinology, 134: 17711781.

15. Bergsten P, Grapengiesser E, Gylfe E, Tengholm A \& Hellman B (1994). Synchronous oscillations of cytoplasmic $\mathrm{Ca}^{2+}$ and insulin release in glucose-stimulated pancreatic islets. J ournal of Biological Chemistry, 269: 8749-8753.

16. Yang $C$, Lee $B$, Chen $T H \&$ Hsu WH (1997). Mechanisms of bradykinin-induced insulin secretion in clonal beta cell line RINm5F. J ournal of Pharmacology and Experimental Therapeutics, 282: 1247-1252.

17. Yang C \& Hsu WH (1997). Glucose-dependence of bradykinin-induced secretion from perfused rat pancreas. Regulatory Peptides, 71: 23-28.

18. Toniyama $\mathrm{H}$, Kushiro $\mathrm{T}$, Abeta $\mathrm{H}$, Ishi I, Takahashi A \& Furukaval A (1994). Kinins contribute to the improvement of insulin sensitivity during treatment with angiotensin converting enzyme inhibitor. Hypertension, 23: 450-455. 